\title{
Effectiveness of Milan Classification in Salivary Gland Aspirations
}

\author{
Zeynel Abidin Tas and Ozgur Kulahci \\ Department of Pathology, University of Health Sciences, Adana City Education and Research Hospital, Adana, Turkey
}

\begin{abstract}
Objective: To determine the effectiveness of Milan system for the evaluation of aspiration cytology to salivary gland lesions classification.

Study Design: Cross-sectional observational study.

Place and Duration of Study: Department of Pathology, Tertier Centre, University of Health Sciences, Adana City Education and Research Hospital, Adana, Turkey from January 2014 to December 2020.

Methodology: Salivary gland aspiration cytology of the last six years was recategorised, according to Milan classification. Risk of malignancy (ROM) and risk of neoplasm (RON) were determined among the subgroups in the cytological materials of 233 patients, who had undergone excisional biopsy.

Results: Forty hundred and eighty salivary gland aspiration cytologies were available, in which 250 (52.1\%) cases were males and $230(47.1 \%)$ were females. The mean age was $52.36 \pm 16.05$ years. When aspiration cytology of 233 patients with resection were evaluated, according to Milan classification, ROM in non-diagnostic category was 9.5\%, ROM in non-neoplastic category was $19.2 \%$, and ROM in neoplasm-benign category was $8.2 \%$. ROM were found $100 \%$ in the suspected malignancy and malignancy categories. There were no patients in the atypia category of undeterminate significance.

Conclusion: In aspiration cytology of salivary gland lesions, Milan system provides useful information in classifying patients for clinical follow-up and treatment. However, it can be said that it is difficult to distinguish between the atypia of uncertain significance and neoplasm categories.
\end{abstract}

Key Words: Salivary glands, Biopsy, Fine-needle, Milan classification.

How to cite this article: Tas ZA, Kulahci O. Effectiveness of Milan Classification in Salivary Gland Aspirations. J Coll Physicians Surg Pak 2022; 32(02):166-170.

\section{INTRODUCTION}

Fine-needle aspiration biopsy (FNAB) is a well-defined method in the diagnosis, staging and follow-up of salivary gland lesions. It has been widely used in the cytological diagnosis of salivary gland lesions in the last few decades, due to its rapid diagnosis, less invasive method, and low complication rate. ${ }^{1}$ Although salivary gland FNAB is affected by a number of factors, such as the technique used, the cytological preparation process, and the experience of the pathologist, it plays an important role in the clinical approach to salivary gland lesions. ${ }^{2}$ It provides important information in the differentiation of non-neoplastic-neoplastic lesions and has a high accuracy rate in the differentiation of benign and malignant neoplastic lesions. ${ }^{3-5}$

Correspondence to: Dr. Zeynel Abidin Tas, Department of Pathology, University of Health Sciences, Adana City

Education and Research Hospital, Adana, Turkey

E-mail: zeynelabidin46@gmail.com

Received: October 11, 2021; Revised: November 08, 2021;

Accepted: December 06, 2021

DOI: https://doi.org/10.29271/jcpsp.2022.02.166
However, cases reported with cytological interpretation without a specific diagnosis due to intra-tumoral heterogeneity, morphological overlaps in salivary gland lesions and lack of a standardised reporting system may cause confusion in the clinician's treatment preference. ${ }^{2,6,7}$ Due to these limitations, the American Society of Cytopathology (ASC) and the International Academy of Cytology (IAC) proposed the Milan classification for aspiration cytology of salivary gland lesions, similar to the thyroid, cervix, pancreaticobiliary, lung and urinary system cytology reporting systems, to establish a standard reporting system. ${ }^{8,9}$ For this purpose, the authors recategorised the salivary gland cytology of the last six years in the clinic, according to the Milan system.

The aim was to evaluate the accuracy of the cytology-histology correlation of the results and effectiveness in the management.

\section{METHODOLOGY}

The results of patients aged 10-90 years, who underwent aspiration cytology due to salivary gland lesion in Adana City Education and Research Hospital between 2014 and 2020, were analysed. The approval from Health Sciences University Adana City Education and Research Hospital Ethics Committee was obtained (Decision No. 1201). All cytological materials were reevaluated by 
two experienced pathologists and recategorised, according to the Milan classification. Milan reporting system non-diagnostic (category 1), non-neoplastic (category 2), Atypia of undeterminate significance (category 3), neoplasm-benign (category 4a), Neoplasm-uncertain of malignant potential (category 4b), suspected malignancy (category 5), malignant cytology (category 6), consists of six main headings. ${ }^{2}$ Patients, who underwent excision after cytology, were correlated with each other. The risk of neoplasm and malignancy was determined for each category. The cases were grouped according to age, gender, localisation and location.

Patients, who had previously undergone salivary gland surgery and/or received chemotherapy/regional radiotherapy, were excluded from the study.

Table I: Cytological evaluation of total and excised cases, according to Milan classification.

\begin{tabular}{|c|c|c|}
\hline & $\begin{array}{c}\text { Cytological } \\
\text { Diagnosis } \\
(480) \\
n(\%)\end{array}$ & $\begin{array}{c}\text { Cytological } \\
\text { results of } \\
\text { excised cases } \\
(233) \\
n(\%)\end{array}$ \\
\hline Nondiagnostic & 62( 12.9) & $21(9)$ \\
\hline Inadequate & 33 & 10 \\
\hline Cyst content & 29 & 11 \\
\hline Nonneoplastic & $118(24.6)$ & $26(11.2)$ \\
\hline Sialadenitis & 56 & 13 \\
\hline Cystic content & 8 & 3 \\
\hline Lymph node/Reactive lymph node & 41 & 5 \\
\hline Granulomatous inflammation & 10 & 3 \\
\hline Abcess & 1 & 1 \\
\hline Normal salivary gland & 2 & 1 \\
\hline AUS & - & - \\
\hline Neoplasm-benign & $236(49.2)$ & $146(62.7)$ \\
\hline Pleomorphic adenoma & 100 & 70 \\
\hline Warthin Tumor & 128 & 70 \\
\hline Lipoma & 3 & 3 \\
\hline Schwannoma & 1 & 1 \\
\hline Myoepithelioma & 3 & 1 \\
\hline Oncocytoma & 1 & 1 \\
\hline SUMP & $25(5.2)$ & $12(5.2)$ \\
\hline Oncocytic neoplasm & 4 & 1 \\
\hline Myoepithelial neoplasm & 4 & 3 \\
\hline $\begin{array}{l}\text { Pleomorphic adenoma with atypical } \\
\text { features }\end{array}$ & 7 & 3 \\
\hline Basaloid neoplasm & 7 & 3 \\
\hline Low Grade Salivary Gland Neoplasm & 3 & 2 \\
\hline SM & $14(2.9)$ & $6(2.6)$ \\
\hline Lymphoma & 4 & 3 \\
\hline Squamous Cell Carcinoma & 4 & 2 \\
\hline Mesenchymal neoplasm & 1 & 1 \\
\hline Mucoepidermiod Carcinoma & 3 & - \\
\hline Acinic Cell Carcinoma & 2 & - \\
\hline Malignant & $25(5.2)$ & $22(9.4)$ \\
\hline Lymphoma & 3 & 3 \\
\hline Squamous Cell Carcinoma & 6 & 6 \\
\hline Metastatic Neoplasm & 7 & 6 \\
\hline Acinic Cell Carcinoma & 2 & 2 \\
\hline Mucoepidermiod Carcinoma & 6 & 4 \\
\hline Adenoid Cystic Carcinoma & 1 & 1 \\
\hline
\end{tabular}

Statistical analysis was performed by using statistical package for the social sciences version 19 (SPSS Inc; Chicago, IL, USA). Descriptive data were given as mean and standard deviation (SD) for quantitative variables in frequencies, and percent for qualitative variables.

\section{RESULTS}

In this study, the salivary glands of FNAB of 480 cases were examined in which 250 (52.1\%) cases were males and 230 (47.9\%) females. The mean age was $52.22 \pm 16.14$ years. The results of cytological and histopathological evaluations, reclassified according to the Milan system, are summarised in Tablel.

Excision material was available in 233 (48.5\%) of the cases. The most common diagnostic category among the cases was neoplasm-benign. It was found to be 236 (49.2\%) in all cases and $146(62.7 \%)$ in excised cases. Whartin tumor was diagnosed most in this category (128). The diagnostic category of suspicious for malignancy had the lowest rate, both among all cases and excised cases. The evaluation of neoplasm and malignancy risk according to the Milan classification of surgically excision cases is summarised in Tablell.

In the non diagnostic category, 11 cases were reported as non mucinous cyst content. One of these cases had low-grade mucoepidermoid carcinoma histology (Figure 1).

Table II: Neoplasm and malignancy risk of associated with Milanclassification.

\begin{tabular}{|l|c|c|c|}
\hline Milan category & $\begin{array}{c}\text { Number of } \\
\text { cases }\end{array}$ & $\begin{array}{c}\text { Risk of Neoplasm } \\
\text { (RON) } \\
\mathbf{n}(\%)\end{array}$ & $\begin{array}{c}\text { Risk of Malignancy } \\
\text { (ROM) } \\
\mathbf{n}(\%)\end{array}$ \\
\hline Non-Diagnostic & 21 & $15(71.4)$ & $2(9.5)$ \\
\hline Non-Neoplastic & 26 & $6(23)$ & $5(19.2)$ \\
\hline AUS & - & - & - \\
\hline Neoplasm, Benign & 146 & $141(96.6)$ & $12(8.2)$ \\
\hline SUMP & 12 & $11(91.7)$ & $5(41.7)$ \\
\hline SM & 6 & $6(100)$ & $6(100)$ \\
\hline Malignant & 22 & $22(100)$ & $22(100)$ \\
\hline $\begin{array}{l}\text { AUS: Atypia of undetermined significance, SUMP: Salivary gland neoplasm of uncertain } \\
\text { malignity potential, SM: Suspicious for malignancy. }\end{array}$ \\
\hline
\end{tabular}

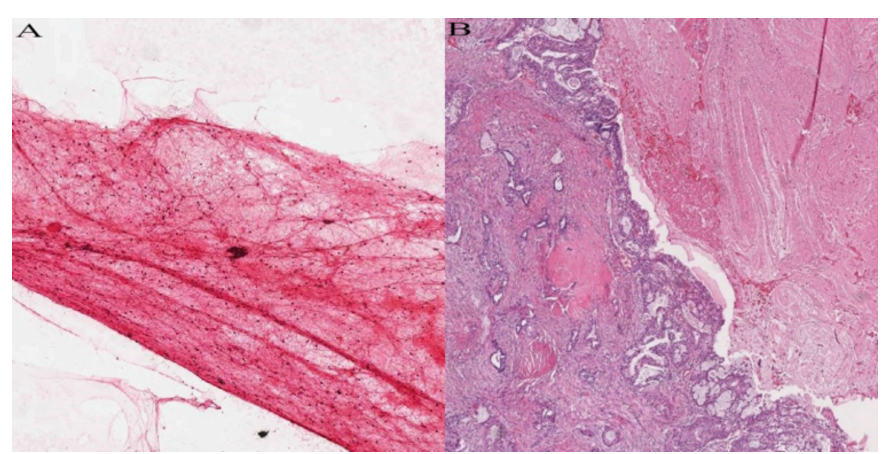

Figure 1: (A) Cystic content containing inflammatory cells in the smear diagnosed as nondiagnostic. (Hematoxylin \& Eosin stain 40x). (B) Histological sections of the sample in Figure 1A. Mucoepidermoid carcinoma with cystic area (upper right). Within the desmoplastic stroma and around the cystic area, an invasive tumor consisting of epidermoid, intermediate and mucocytes is seen at varying rates. (Hematoxylin \& Eosin stain 40x).

Ten cases were reported as insufficient material and one of these cases was diagnosed as adenoid cystic carcinoma. 
There was discordance in the histological examination of six cases in the non-neoplastic category. There was histological discordance in 9 cases reported as warthin tumor (Figure 2) and in 10 cases reported as pleomorphic adenoma in the neoplasm-benign category. Cases with cytology-histology discordance are summarised in Table III.

No cases were reported in the AUS. There were 12 case excisions in the SUMP category. Five cases were reported as malignant.

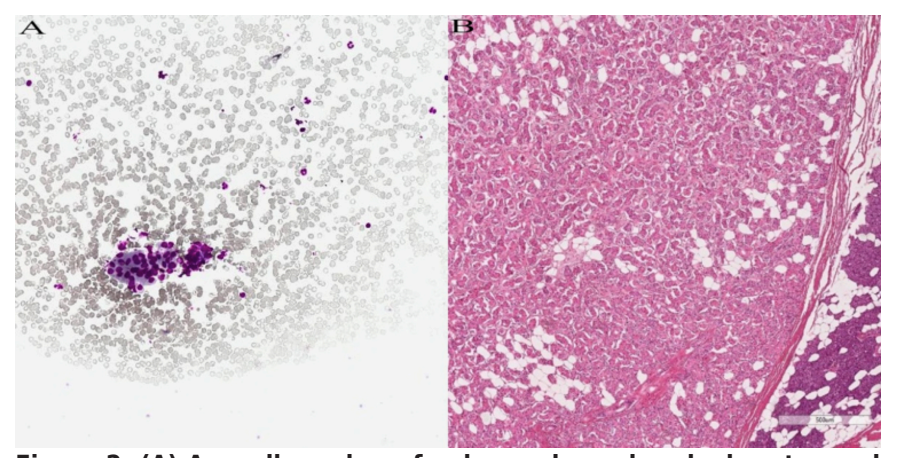

Figure 2: (A) A small number of polymorphonuclear leukocytes and lymphocytes are observed in the erythrocytic background. Cell group with oncocytic appearance in the central area. It was diagnosed with a Whartin tumor. (May Grunwald Giemsa stain 40x). (B) Histological sections of the case in Figure $2 A$. In the normal salivary gland, thin fibrous capsules with separated eosinophilic cytoplasm, oncocytic cells arranged in a follicular pattern, and lipocytes in between are observed. Histologically, oncocytoma was diagnosed. (Hematoxylin \& Eosinstain 40x).

Table III: Cases with Cytology-histopathology discordance.

\begin{tabular}{|c|c|c|}
\hline Nondıagnostıc & FNAB (n) & Histopathological diagnosis (n) \\
\hline Cyst content & 11 & $\begin{array}{l}\text { Warthin Tumor (7) } \\
\text { Lymphoepithelial cyst (2) } \\
\text { Pilomatrixoma (1) } \\
\text { Low grade Mucoepidermoid } \\
\text { carcinoma(1) }\end{array}$ \\
\hline \multirow[t]{5}{*}{ Inadequate } & 6 & Basal cell adenoma (1) \\
\hline & & Warthin Tumor (2) \\
\hline & & Lymphoepithelial cyst (1) \\
\hline & & Lipoma(1) \\
\hline & & Adenoid cystic carcinoma (1) \\
\hline \multicolumn{3}{|l|}{ Nonneoplastıc } \\
\hline Sialadenitis & 1 & Lipoma \\
\hline Abscess & 1 & Squamous cell carcinoma metastasis \\
\hline $\begin{array}{l}\text { Granulomatous } \\
\text { inflammation }\end{array}$ & 1 & Malignant melanoma metastasis \\
\hline \multirow{3}{*}{ Reactive lymph node } & \multirow{3}{*}{3} & Fibrohistiocytic neoplasm (1) \\
\hline & & Epithelial/myoepithelial carcinoma (1) \\
\hline & & Lymphoma (1) \\
\hline \multicolumn{3}{|l|}{ Neoplasm-Benıgn } \\
\hline \multirow[t]{8}{*}{ Warthin tumor } & 9 & Abscess (1) \\
\hline & & Pleomorphic Adenoma (1) \\
\hline & & Oncocytoma (1) \\
\hline & & Inflammatory myofibroblastic tumor (1) \\
\hline & & Lymphoepithelial cyst (2) \\
\hline & & Chronic Sialadenitis (1) \\
\hline & & Squamous cell carcinoma metastasis (1) \\
\hline & & Pleomorphic Adenoma ex Carcinoma (1) \\
\hline \multirow[t]{5}{*}{ Pleomorphic adenoma } & 10 & Pleomorphic Adenoma ex Carcinoma (4) \\
\hline & & Squamous cell carcinoma metastasis (2) \\
\hline & & Malignant melanoma metastasis (2) \\
\hline & & Adenoid cystic carcinoma (1) \\
\hline & & Basal cell adenoma (1) \\
\hline
\end{tabular}

\section{DISCUSSION}

FNAB is a method that is widely used by clinicians in the first approach to salivary gland lesions. ${ }^{10} \mathrm{After}$ the recommendation of ASC and IAC in 2015 and the work of Rossi et al., the effectiveness of the Milan classification system and the risk of malignancy (ROM) were evaluated in various studies. ${ }^{7}$ In various studies, the neoplasm-benign category was found as the most common category. The rates in these studies were found to be $36.9 \%, 33 \%$, and $31.4 \%{ }^{11-13}$ In this study, neoplasm-benign category was the most common with frequency of $49.2 \%$. This high rate in the series may be due to regional or interracial differences.

Excision was made in $48.5 \%$ (233) of the cases. When the histologically examined cases were classified as benign neoplasm, malignant neoplasm and non-neoplastic, $63.9 \%$ of the cases were diagnosed as benign neoplasm, $22.3 \%$ as malignant neoplasm and $13.8 \%$ as nonneoplastic lesion. In a meta-analysis study, in which 4,506 cases were examined histologically, $62.0 \%$ of cases were diagnosed as benign neoplasm, $26.0 \%$ for malignant neoplasm, and $12.0 \%$ for nonneoplastic. ${ }^{14}$ Due to the similarity of these ratios, it can be concluded that this series has a similar distribution with the studies in the literature. When the cases with surgical excision were evaluated, the non-diagnostic category comprised $9 \%$ of the cases and ROM was determined as $9.5 \%$. Most of the cases in this category were lesions of cystic nature. Only three cases were of solid lesions. These findings show that careful evaluation of the cyst content, especially in cystic lesions, and non-diagnostic diagnosis incases with insufficient cellular elements, is the correct approach. As a result, it is important for the pathologists to know the ultrasonographic features of the lesion. Although the expected ROM in this category is $25 \%$, many different studies have found different rates, as in this study. ${ }^{13-16}$ More importantly, rapid onsite evaluation can reduce rate of non-diagnostic category and provide more advantages for patients, and reduce the workload for healthcare professionals. The expected ROM in the non-neoplastic category is $10 \%$. In a meta-analysis study, ROM in this category was found to be in the range of $0-37 \%$, with an average of $10.2 \% .{ }^{14}$ While ROM in this category was $17 \%$ in one study in the USA, and it was $17.4 \%$ in another study. ${ }^{12,19}$ In this series, ROM was $19.2 \%$. Possible inappropriate sampling in these cases could explain this high rate.

No case was reported in the AUS. This may indicate that atypical cellular elements observed in smears are mostly evaluated in the neoplasm category.

It is recommended that ROM should be below $5 \%$ in the benign neoplasm category. ${ }^{15}$ In the meta-analysis study of Wei et al., the mean ROM in this category was found to be $3.4 \%(0-13 \%){ }^{14}$ In various studies, ROM in this category was found to be $1.9 \%$, $4 \%, 5 \%, 5 \%, 6,9 \%, 2.1 \%, 7.3 \%$, respectively. ${ }^{11-13,16-19}$ In this study, the authors found ROM in this category to be $8.2 \%$. Tumor heterogenenity, especially in pleomorphic adenoma excarcinoma cases, may explain the high malignancy risk as found in this category. However, the fact that no cases were reported in the AUS suggests that the cytology in this group may have been included in the neoplasm category as mentioned before, and therefore may be one of the reasons for the high 
malignancy rate found in the benign neoplasm category.

The expected ROM in the SUMP category was $35 \% .{ }^{15}$ In other studies in the literature, this rate was found to be $26.7 \%, 33 \%$, $34.2 \%, 40 \%, 50 \%, 44.4 \%$ and $50 \%$, respectively. ${ }^{11-13,16-19}$ In this series, ROM was $41.7 \%$. The results show that are important in terms of being a warning to the clinician in cases reported as basaloid neoplasm and low-grade salivary gland neoplasm in the SUMP category, highlighting the addition of an explanatory note for the differential diagnosis of these lesions.

The expected ROM in SM category was $60 \% .{ }^{15}$ In other studies in the literature, this rate was found to be $100 \%, 67 \%, 92.9 \%$, $60 \%, 66.6 \%$, and $60 \%$, respectively. ${ }^{11-13,16-18}$

The ROM was found to be $100 \%$ in this study. This value was higher than many similar studies. It can be said that this high rate shows that we tend to evaluate some cases in the malignant category as a subcategory SM. Expected rate ROM in malignant category was $90 \%{ }^{15}$ In this study, all cases in the malignant category were histologically malignant (100\%). In similar studies, this rate was $100 \%, 100 \%, 92.3 \%, 93 \%, 87.5 \%$, and $100 \%$, respectively. ${ }^{11-13,16-18}$

The main limitations of this study are the higher frequency of lymphomas and metastatic carcinomas in SM and malignant categories than primary salivary gland malignancies. Since the head and neck region is rich in lymph nodes, it should be kept in mind that metastasis to lymph nodes in and around the salivary glands may be more common.

\section{CONCLUSION}

Milan classification seems to be a useful categorisation system in terms of creating a common language between the pathologists and the clinicians in the approach to salivary gland lesions in this study and making a clear-risk classification for the patients. The fact that ROM was low in the non-diagnostic category and high in the non-neoplastic, benign neoplasm, and SUMP categories in this study, reveals that appropriate sampling, rapid onsiteevaluation, and cytopathological experience are important. The fact that few cases were reported in many studies in the AUS and SUMP categories, as in this study, may indicate a confusion in pathologists, especially for these two groups. For this reason, determining the stricted cytomorphological criteria and using immuno-histochemical and molecular methods together by obtaining cell block, can help in determining the categories in the classification, especially in the differentiation of lesions with morphological overlap.

\section{ETHICAL APPROVAL:}

The approval from Health Sciences University, Adana City Education and Research Hospital Ethics Committee was obtained (Decision No. 1201).

\section{PATIENTS' CONTENT:}

Patients' consent was not obtained as the study was designed on retrospective pathology archive preparations.

\section{CONFLICT OF INTEREST:}

The authors declared no conflict of interest.

\section{AUTHORS'CONTRIBUTION:}

ZAT, OK: Conception or design of the work; or the acquistion, analysis, or interpretation of data for the work; drafting the work or revising it critically for important intellectual content; final approval of the version to be published. Agreement to be accountable for all aspects of the work in ensuring that question related to the accuracy or integrity of any part of the work are appropriately investigated and resolved.

\section{REFERENCES}

1. Jan IS, Chung PF, Weng MH, Huang MS, Lee YT, Cheng TY, et al. Analysis of fine-needle aspiration cytology of the salivary gland. J Formos Med Assoc 2008; 107(5):364-70. doi: 10.1016/S0929-6646(08)60101-1.

2. Song SJ, Shafique K, Wong LQ, LiVolsi VA, Montone KT, Baloch Z. The utility of the Milan System as a risk stratification tool for salivary gland fine needle aspiration cytology specimens. Cytopathology 2019; 30(1):91-8. doi: 10.1111/cyt.12642.

3. Wang H, Fundakowski C, Khurana JS, Jhala N. Fine-Needle Aspiration Biopsy of Salivary Gland Lesions. Arch Pathol Lab Med 2015; 139(12):1491-7. doi: 10.5858/arpa.2015-0222RA.

4. Colella G, Cannavale R, Flamminio F, Foschini MP. Fineneedle aspiration cytology of salivary gland lesions: A systematic review. J Oral Maxillofac Surg 2010; 68(9): 2146-53. doi: 10.1016/j.joms.2009.09.064.

5. Cibas ES, Ducatman BS. Cytology: Diagnostic Principles and Clinical Correlates. Philadelphia, PA, Elsevier, 2014.

6. Savant D, Jin C, Chau K, Hagan T, Chowdhury $M$, Koppenhafer J, et al. Risk stratification of salivary gland cytology utilising the Milan system of classification. Diagn Cytopathol 2019; 47(3):172-80. doi: 10.1002/dc.24063.

7. Rossi ED, Faquin WC, Baloch Z, Barkan GA, Foschini MP, Pusztaszeri $\mathrm{M}$, et al. The milan system for reporting salivary gland cytopathology: Analysis and suggestions of initial survey. Cancer Cytopathol 2017; 125(10):757-66. doi: 10.1002/cncy.21898.

8. Vallonthaiel AG, Kaushal S, Jangir H, Rajendran HK. Application of the milan system for risk stratification and its comparison with a previous reporting system of parotid gland cytopathology in a tertiary care centre. Acta Cytol 2018; 62:352-9. doi: 10.1159/000492051.

9. Rossi ED, Faquin WC. The Milan system for reporting salivary gland cytopathology (MSRSGC): An international effort toward improved patient care-when the roots might be inspired by leonardo da vinci. Cancer Cytopathol 2018; 126(9):756-66. doi: 10.1002/cncy.22040.

10. Layfield LJ, Glasgow BJ. Diagnosis of salivary gland tumors by fine-needle aspiration cytology: a review of clinical utility and pitfalls. Diagn Cytopathol 1991; 7(3):267-72. doi: 10.1002/dc.2840070311.

11. Thiryayi SA, Low $Y X$, Shelton D, Narine N, Slater D, Rana DN. A retrospective 3-year study of salivary gland FNAC with categorisation using the Milan reporting system. 
Cytopathol 2018; 29(4):343-8. doi: 10.1111/cyt.12557.

12. Hollyfield JM, O'Connor SM, Maygarden SJ, Greene KG, Scanga LR, Tang $S$, et al. Northern Italy in the American South: Assessing interobserver reliability within the milan system for reporting salivary gland cytopathology. Cancer Cytopathol 2018; 126(6):390-6. doi: 10.1002/cncy.21989.

13. Viswanathan K, Sung S, Scognamiglio T, Yang GCH, Siddiqui MT, Rao RA. The role of the milan system for reporting salivary gland cytopathology: A 5-year institutional experience. Cancer Cytopathol 2018; 126(8):41-51. doi: 10.1002/cncy. 22016.

14. Wei S, Layfield LJ, LiVolsi VA, Montone KT, Baloch ZW. Reporting of fine needle aspiration (FNA) specimens of salivary gland lesions: A comprehensive review. Diagn Cytopathol 2017; 45(9):820-7. doi: 10.1002/dc.23716.

15. Rossi ED, Baloch Z, Pusztaszeri M, Faquin WC. The Milan system for reporting salivary gland cytopathology (MSRSGC): An ASC-IAC-sponsored system for reporting salivary gland fine-needle aspiration. J Am Soc Cytopathol
2018; 7(3):111-8. doi: 10.1016/j.jasc.2018.02.002.

16. Layfield LJ, Baloch ZW, Hirschowitz SL, Rossi ED. Impact on clinical follow-up of the Milan System for salivary gland cytology: A comparison with a traditional diagnostic classification. Cytopathol 2018; 29(4):335-42. doi: 10. 1111/cyt.12562.

17. Katta R, Chaganti DP. Application of the Milan system of reporting salivary cytopathology - A retrospective cytohistological correlation study. J NTR Univ Health Sci 2019; 8:11-7.

18. Hafez NH, Abusinna ES. Risk assessment of salivary gland cytological categories of the milan system: A retrospective cytomorphological and Immunocytochemical institutional study. Turk Patoloji Derg 2020; 36(2):142-53. doi: 10. 5146/tjpath.2019.01469.

19. Rohilla M, Singh P, Rajwanshi A, Gupta N, Srinivasan R, Dey $P$, et al. Three-year cytohistological correlation of salivary gland FNA cytology at a tertiary center with the application of the Milan system for risk stratification. Cancer Cytopathol 2017; 125(10):767-5. doi: 10.1002/cncy.21900. 